\title{
Discussion Method Teaching: A Practical Guide
}

\section{William M. Welty}

Pace University

Those of you who are interested in discussion method teaching are probably convinced that improving interactive skills in the classroom will improve your teaching. Both learning theory and common sense suggest that finding ways to involve students actively in what they are supposed to be learning is a worthwhile undertaking. The converse makes the point more effectively. There is nothing so depressing as to walk the halls of the contemporary American university and see faculty member after faculty member, barricaded behind lecterns, talking, talking, talking to students slumped in tablet-arm chairs, their body language belying their involvement in the education proffered to them.

What happens in far too many college classrooms in the United States is a poor substitute for education, but most faculty members do not know what to do about it. They blame the university administration for its admission policies, the students for their boorishness and lack of good old-fashioned work ethic, the secondary school system for its failure to instill the basics, the family for its lack of moral fiber, the culture for its rock music and mindless television pap, and on and on. Blaming everything outside might lay a smoke screen around the college classroom so that no one will notice the rapidly expanding educational kill rate in American higher education. But students notice and understand, and parents and state legislatures, who foot the outrageous tuition bills, are beginning to notice as they compare the value added with the costs of a college education.

Most faculty in American colleges and universities teach what they were taught in the way that they were taught. They value content and theory and feel that the most effective way to communicate that is by content-laden, theoretically-based lectures. Even when feeling uneasy 
about the numbers of students who "aren't getting it," there seems no other way. Attempts at discussions degenerate into directionless bull sessions or meaningless debates in which the facts are all wrong and the logic nonexistent. Such discussions usually provoke the best students to complain that they "didn't pay all this money to hear another student sound off. You can get that for free in the student union."

I suggest there is a way to energize your classrooms, to excite a much higher percentage of your students, and to add more value to their education. You can get out from behind your lectern and still communicate content and theory. But to do this you will have to pay far more attention than you have in the past to questions of teaching and to the teaching methods you are using. What follows here will help you to begin thinking in an organized way about these process issues.

I came to understand the discussion teaching process through using the case method in my work as a faculty member in a graduate school of business. Much of what I have to say derives from the work of those who have perfected the case method of teaching. It is the premise of this paper that the case method used successfully in business schools can be made applicable to discussion teaching for the arts and sciences, and that those teaching methods that make for successful discussion classes can be learned by interested faculty members. While the "case" may be a Yeats poem or an 18th-century census or a Reagan speech, the discussion process is the same and works by the same rules.

This paper does not contend that discussion teaching is the only, or even the best, pedagogical method available to college teachers. Successful college teaching demands that the teacher have available a number of techniques to use at the proper time and in the proper situation to maximize learning. One of those techniques, underutilized because most faculty do not understand its dynamics, is the discussion. In a sense, the technique described here is really the first step away from the lecture method of teaching, for it is a method of leading a discussion in which a good deal of authority and control remain in the hands of the discussion leader and in which a good deal of content and theory can be imparted by the discussion leader. The authority issue is an important one. Many advocates of discussion method teaching argue that for true learning to take place in the discussion class, the faculty member must relinquish authority and control and seek to help empower students so that they are able to learn for themselves on a continuing basis. I do not dispute that as an ultimate goal, but for the newly converted discussion leader, the method must provide an orderly transition from the lecture method. Once 
the process becomes more familiar, the teacher may then be willing to consider methods that relinquish more authority to the students. The authority issue is an important one-keep it in mind as you grapple with the suggestions which follow.

\section{Preparation Before Class}

When I demonstrate discussion method teaching to colleagues, the question most often asked has to do with pre-class preparation. Let's begin, then, by taking a look at that process, keeping in mind that preparation for a discussion class needs to marry process and content - we are looking for ways to communicate, to enliven, to bring home the content; we want to find ways to help students to internalize the theory.

\section{Read the Assigned Material}

It should go without saying that the teacher must be very familiar with the reading assigned for discussion. He or she must be ready for almost any nuance to be discovered, for almost any connection to be made. The more thinking and reading done about the assigned material, the better prepared the teacher will be for the discussion about it. Most faculty do this as a matter of course, but as you gain experience with the discussion process, you will find that assignments that were once familiar take on new meanings and new connections with other parts of the world as many different, and now inquiring, minds actively grapple with it.

\section{Decide on Important Concepts and Outline}

Once you are sure you have a good grasp of the assigned material and its many nuances, decide what important concepts you want to be sure are understood by every student in your class. Ask yourself, "Why did I assign this material?" Important concepts usually have somewhat important sub-concepts, and before long we content-theoretical types are several layers deep in important concepts. Such thoughts usually lead to an outline, and soon there emerges a logical pattern that we can hope the discussion will take. Such an outline should make you more comfortable, but be sure the outline reflects in layers or levels what is most important and what is less, for in the heat of a good discussion you will have to discard getting at some of the less important concepts for the sake of making sure the more important ones are really understood.

At this point you should, as well, make notes about specific facts important people and their relationships, chronology, sets of figures, any 
particulars that bear on the matters you feel are important. Nothing destroys the attempt to communicate the necessity of reasoning from the facts as much as a discussion leader who cannot keep the details straight. It is important to communicate this message to your students early in the discussion process, for the euphoria of the free-wheeling exchange of ideas is sometimes so overwhelming that even the best students forget to deal with the concrete aspects of the material.

\section{A Question Outline}

Once you are sure of your grasp of the facts, prepare a question outline to match your concept outline. It is important at this stage that you carefully think of questions that will promote discussion, not answers, about the concepts you want understood. If you are having trouble promoting discussion in your classes now, examine the kinds of questions you are asking. Do they signal that you know the answer and are asking to see if the students do? "What did the author say were the causes of the Civil War?" Such questions are the kind that promote participation from only those students anxious to show they know exactly what the teacher is looking for. Most students are programmed to think that there is only one right answer, that the teacher knows it, and that he or she will reward those who know it and punish those who do not. (Guess who programmed them.) Such thinking spells doom for a discussion class. Serious discussion teachers must work at overcoming this mind-set and seek to encourage creative and critical thinking, not memorization and not single solution models. Sometimes, just the way you phrase a question makes a real difference. Instead of asking what the text said were the causes of the Civil War, one might say, "Let's see if we can understand why the Civil War began. Lori, can you suggest a reason?"

Build your question outline at least as many layers deep as your concept outline-one group of very general questions that covers the whole assignment and serves as a macro-outline to guide you through the class, then groups of more specific questions about different aspects of the outline that will serve to expose important points - probes, they might be called. Try to anticipate possible responses to the questions and think through what can be done with them - how they can be used positively - to move the class toward more understanding. Ask smaller, easier-to-dealwith questions first; work up slowly to global, more thought-provoking questions. For instance, in business cases or teaching cases, I normally start with analysis questions - "What is going on here?" - and use the analysis to move to action questions - "What should the protagonist do? 
What are the costs and benefits of doing what you suggest?" - and to broader, more philosophical questions - "Should we look to maximize long- or short-term?"

With a general and a specific outline of questions to guide your discussion, you must think carefully about the really important questions - beginning, transition, conclusion - and highlight them in your outline. You should know almost exactly what question, word for word, you are going to use at these important times, and perhaps even whom you are going to ask. Thinking ahead in such careful detail allows the leader more control over the discussion, something the beginning discussion teacher will probably welcome. Ask questions and more questions and still more questions. If you hear yourself making too many declarative statements, the discussion is not going well. In class, instead of talking, you should be listening and formulating your next question. Think of your lecture as becoming a series of interrogative statements. For more specific help, there are several articles listed in the bibliography; the best is the article by John Andrews, which gives specific examples of different kinds of questions. In addition, copies of teaching notes which accompany the cases cited in the bibliography include examples of discussion-provoking questions and question outlines.

\section{A Board Outline}

A good discussion leader should make use of the blackboard to help organize the discussion, which at times will seem to be going off in all directions. The board, in fact, is another very powerful control mechanism for the discussion leader. You choose what to write on the board and where to write it. Want to pump up a shy student's self-confidence? Write his contribution on the board. Even more? Underline it! Want to calm an overly aggressive contributor? Do not bother to inscribe her comments. What is written on the board takes on a huge importance. Early in the semester, when you are still working to build a group's collective confidence in the discussion process, filling the board with a well-organized analysis of the material will do miracles. "My gosh, look what we did!" students will say as they admire the board at the end of the class period. "And I didn't think I understood a thing Plato said."

Whatever you write on the board, and it can't include everything that is said in a discussion class, you must think ahead of time just how you want the board to look at various times in the class. Therefore, prepare a board outline to help guide what to write down and where. Do not write on the board haphazardly. Do not make "chicken tracks" on the board. 
Carefully consider what you want on it before you use the chalk. Used carefully, it is a great control mechanism, a great reward/punishment mechanism, and a great guide for inveterate note-takers. You might, for instance, wish to use the board to symbolize how logically the discussion is proceeding by writing things in neat columns from left to right, drawing vertical lines to indicate when to move on to a new topic. Or, you might want to take comments on many different ideas early in the discussion, using several boards to record them, allowing more reflective thought later in the discussion to highlight relationships. You might even want the board to communicate disorder. (In a discussion I have done on the 1981 Reagan economic plan, the class through discussion builds an econometric model that is recorded on the board. By the end of the discussion of the feedback relationships of the various inputs, the board looks something like a Jackson Pollock painting, an effective comment on voodoo economics.)

This ancient audiovisual aide, not subject to the vagaries of modern technology and its minions, is a powerful technological tool for the discussion teacher - more powerful even than Mark Hopkins' log. Do not use it casually or without thinking through its impact.

\section{Knowing Your Students}

You are leading a discussion because you want the students in the class to learn something from that discussion-after all, they are the important ones in the process. To maximize that learning, you must know them as more than a number on your roster. Each is different, each learns differently, each responds differently to the various stimuli of the discussion class. What are their strengths and weaknesses? What kinds of participation will build on their strengths or improve their weaknesses? If you are going to think about whom to ask certain questions, whom to turn to during certain times in the discussion, you need to know what to expect in response. A number of faculty I know were greatly impressed with the performance of the various discussion leaders, including the new president of Yale, who led the seminars on the PBS television series The Constitution: That Delicate Balance a few years ago. One of the keys to the success of those discussions was how much each discussion leader knew about the participants, each of whom was a public figure. To move the discussion one way or another, the leader knew almost exactly whom to ask.

Before every class, look over your roster and update your knowledge of each student and what you hope to get from him or her in the class you 
are planning - perhaps even set objectives for each student for each class. You will not meet all your objectives, but it is an important obligation to try. As long as they are sitting in your class, you have the responsibility to help all of your students and to add some value to their education - not just the smart ones or the ones who give you positive feedback, but every one of them.

\section{Looking at the Whole Semester and the Whole Institution}

Any single class outline cannot stand alone; it must fit with the plan for the entire semester. This plan must include not only what content to cover, but how the discussion process can be enhanced as the semester progresses. Most of the institutions in which we teach condition students to be passive in class. Therefore, in planning the semester, remember that you are probably struggling with an institutional culture that discourages active participation. Work up to it slowly; schedule topics and discussions keeping in mind that you are reorienting behavior patterns and that this will take more than one class. If you seek to encourage true discussion, you cannot do it by having a discussion here and a discussion there - it has to be a regular and substantial part of the course.

I would suggest a syllabus for a discussion course that errs on the side of complexity and length. I prefer a class-by-class outline that includes several study questions and background readings for each reading assignment to be discussed. The better prepared the participants are, the better the discussion; if the course outline helps this, you have sent the right message.

\section{Physical Setting}

All the trouble that you have taken in preparing for the discussion class will be for naught if you are trapped in a physical setting that impairs the discussion process. The best laid plans for the board will be useless if you find a room with flip charts and marking pens. Nailed down tablet-arm chairs in a lecture hall would tax the abilities of Harvard's finest case instructor. I would strongly advise getting on the friendliest of terms with your institution's space coordinator and making him or her aware of your special mission and its environmental requirements. Whatever your room assignment, never let the space in which you are scheduled to teach surprise you. Know ahead of time what will be there and what you will need to do to improve it. 


\section{The Ideal}

To begin with, let's describe the components of the ideal room for a discussion course: tables and executive-type swivel chairs for the students, arranged in a U-shape; a small table in the front for the instructor; board space on at least two walls; room enough for the instructor to roam around the room. The U-shape is the single most important environmental factor for the discussion class, for it allows all the participants to see each other, therefore promoting interchange, and, by providing a good deal of space for the leader to use, enhancing authority and control in a situation in which many instructors feel powerless. Tables provide the students with a natural protection against the terror of the discussion process (protecting their ideas and their knees from uncomfortable analysis). They can lean forward without threatening others. Discussion leaders welcome the tables as well - there is terror on both sides in the discussion process and the leader can challenge a participant without physical threat. Swivel chairs obviously increase the freedom with which all parts of the room can be used and promote participant interchange.

The discussion leader needs enough space to move about the room in order to energize the discussion when necessary; ideally, enough space to be able to contact every student in the room. The discussion leader must also be able to get to the board whenever he or she wishes without interfering with the discussion flow. If you are going to bring the outline and notes on which you worked so diligently, you need a place to put them, along with watch, rosters, handouts, and so on. A smaller table in the front, not enclosing the $U$, and certainly not to hide behind, serves the purpose. Psychologically, it is nice to have it there, to know your notes are there, even if you do not refer to them. I would add to this utopia a name card for each student (tent cards made out of oaktag), so that you can refer to each student by name and so that students can refer to each other by name. For ten cents a student, name cards do wonders for group cohesion and mutual respect.

\section{Usual Situation}

I'll wager that 90 percent of American college classrooms were designed and furnished by the same architectural firm that designed and furnished those in which I teach. They are square or rectangular boxes with no windows, with one always-dirty blackboard (green, if it is a new building), tile floors, fluorescent lighting, tablet-arm chairs set in rows, the regularity of which is reinforced daily by the same custodial staff that never 
cleans the blackboard. Such physical surroundings do not encourage education and are certainly at least partly responsible for the failure of many valiant attempts to make a discussion class work.

I do not think that a discussion class can work in a room in which the students are seated in rows facing an instructor barricaded behind a lectern. The participants must be able to see and to talk to each other, and the leader must be physically able to move to any part of the room and to any student. When the leader stands at the front of rows of students, all discussion comes at him or her; any interchange is always student to instructor to another student. You want to encourage straight-line communication, from student to student. If you are confronted with the typical physical environment, come early and move the furniture to approach the ideal described above. If you cannot come close to the ideal, be ready to compensate in other ways. If you get stuck in a room with fixed seating, get the room changed somehow - the end will justify the means.

Many discussion teachers prefer to arrange the classroom in a circle or to request a "seminar" room with one large table and seats all around it. I do not like the circle shape in either of these variations for several reasons. Most importantly, it inhibits the control that the leader can comfortably exercise. With all seats in a circle or around a table, the leader must sit down; hence, using the board or physical movement to guide and shape discussion becomes a clumsy interruption in the natural discussion process. To me, the center of a circle or most of a large oak table is, at best, a symbolic power vacuum, at worst, wasted space in an environment in which space is a scarce resource. Either situation certainly severely limits the number of students who can participate in the class. Further, outlines and notes of any detail are all but impossible to spread on the tablet of a tablet-arm chair and risk being relied on too heavily if they are in front of you on the seminar table.

Moving to a discussion mode of teaching will not in every case make you the enemy of the administration. Class size need not be limited to the usual "seminar" size. If you have the proper space, classes of 30 to 40 can proceed comfortably. And, if your institution is a Harvard Business School clone with physical facilities built especially to accommodate case discussion, 80 can be an effective class size. Perhaps your vice president for environmental design would be amenable to a deal-better discussion class facilities in exchange for a larger average class size. 


\section{The Class}

If you have followed the procedures suggested so far, you have already spent a good deal of time preparing for a single class and physically exhausted yourself moving furniture. But, as in any endeavor, the better job you do in preparation, the better the actual class should go. Once the discussion begins, so many things will be flying through your mind as you try to keep it on track, you do not want to have to worry about details that could have been worried about before. Arrive early enough to get yourself organized in the classroom - chairs moved, boards erased, lecterns moved out of the way, and notes spread on your table.

\section{Beginning the Class}

Thoughts differ on this, but I prefer easing my way into the day's discussion by talking informally with the class about housekeeping matters and events of the week that might relate in some way to the course, and responding to questions. I think this loosens the tension, both mine and theirs, before we get to the business of the day - discussing the assignment. As a transition into the discussion, a short introduction by the instructor explaining where the assignment fits in with the overall scheme of the course and making some general opening remarks about it - usually is in order; but the shorter, the better.

Presumably, you have thought through carefully in your preparation just exactly what question you are going to ask. Your choice at this point is an important process question. Do you want to ask for volunteers or do you want to call on someone? If you decide on calling, you have yet another choice-giving the student some time to think about the question or requiring an answer immediately - cool calls or cold calls, as the jargon goes. The choice of volunteering versus calling is an important one for the mood of the class. I prefer to stay with volunteers, hoping to play down the sort of recitation syndrome that you get when you have set up a cold or cool call environment. All things being equal, I would want to think that those students who participated wanted to do so because they had something to contribute, not because I wanted them to participate (to test them, perhaps?). But you have to work hard to create an environment in which a large number of students volunteer. Usually the same hands shoot up in every class in response to, and sometimes before, your first question. In an environment where everybody expects to be called, it is easier to encourage the shy and those who need more help in verbalizing their ideas. 
Certainly, the larger the class, the more likely you are to have to force participation, and the earlier you start this in the semester, the easier it is for all concerned. Cool calling at the beginning of such a class, therefore, seems a good compromise. Before you do anything else, state your first question, ask a particular student to think about an answer, and ask another student to serve as a backstop. Then go on to your introductory business and when you get to the discussion, the student has had five to ten minutes to think about an answer. Early in the semester, I begin the class with a question that has accompanied the assignment in the syllabus. As students gain experience in the discussion method, I like to ask a different question, one they have not specifically thought about in their preparation. The discussion proceeds differently depending on which of these choices you make.

\section{Questioning, Listening, Response}

Now begins the guts of the discussion class. The student, however he or she got recognized, is talking, and is not answering the question in any of the many ways you so painstakingly thought out the night before. How do you respond? Do you write on the board? Do you try to silence her? Do you correct her? There are no sure answers, and there is a great deal of existential uncertainty. The key skills at this point are listening skills, a set of behaviors that college faculty probably have not practiced since graduate school. You will get plenty of practice if you stick with discussion teaching. Make sure at the first level you are hearing exactly what the speaker is saying. In order to test your hearing, you need to give the speaker some feedback - writing what he says on the board or repeating what is said. Beyond that, one needs to listen to the subtext of the student's comments - the meaning behind the words, what they reveal about what is important to the speaker.

Discussion teachers can learn much from the counseling profession, especially the process called active listening. In that process, you as teacher must communicate back to the speaker that you understand what was said - text and subtext. But beyond that you must communicate what is important to you, the teacher, so that you and the student can work together to take some action - to learn, in this context. The tricky part in the discussion classroom is that you have $\mathbf{4 0}$ other people who have to be listened to and communicated with, and who must learn as well to practice active listening skills. The better you listen and the better you get all your students to listen, the better by the square of that will your discussion go. 
What goes on in the discussion class is a very involved and very complex process in which you must use questioning, listening, and response activities to shape the discussion toward the ends you have thought important in your planning. You must intervene at times with a question or a summary or a bridge from an earlier remark to help move the discussion toward your goals. At other times, you must allow discussion to take place without any obvious control on your part. In this sense, this questioning, listening, response process is your ultimate source of power in the discussion classroom, more important than blackboards, U-shapes, tables, and room to roam.

While using questioning and active listening to move the class toward the goal you have set, you have some other objectives to meet as wellwhich students are understanding, which are not; who needs to be helped, who needs some stroking, who some quieting. In addition, in the concern for keeping the discussion on track, one should not force the outline so much that the free flow of ideas is discouraged. A good discussion leader in this sense encourages a kind of "controlled spontaneity" - maintaining a balance between free-wheeling discussion and control. I like to think of the discussion process as a set of concepts that the discussion circles around, gets at an understanding of from one angle, moves away from for a while, and then returns to from another angle-certainly not a linear process, perhaps a more holistic one. The objective, as much as covering your outline, is to engage true discussion, to get the students to talk to each other in a meaningful way. When that begins to happen, back away and let it go-it is an important moment.

\section{Body Language}

To teach successfully by the discussion method, especially in the physical environment I have suggested, you must learn to make yourself aware of the message your body is communicating. Nothing conveys more clearly to students the boredom and irrelevance of a modern university education than the lecturer leaning on his lectern. On the other hand, the successful discussion class is led by a person constantly in motion; hence, the need for the space to give the discussion leader the freedom to move toward a speaker or away, to stand between disagreeing parties or behind one party or the other, to rush to the board to write a telling comment, to roam through the aisles in search of new participants or to stir excitement among the alienated or to see how the board looks from the point of view of the back row. The leader can turn up the intensity by more movement or can calm a class into serious reflection by sitting and letting discussion 
proceed by itself. With more freedom to move, options are expanded. Keep in mind though that each movement you make, each stance that you take, where you put your hands, how your face reacts, in short, everything your body does, communicates something to your audience. You must be aware at all times (like an actor on the stage) what your body is saying.

\section{Sense of Time}

One of the most difficult things to control in a discussion is timenothing seems to disappear so quickly in a good discussion and to last so long in a poor one. Every discussion plan should have a beginning, a middle and an end, with some time targets for each thought out in advance. You have a given amount of time at your disposal. How much will you spend on each major part of your outline? Great teachers, like great athletes, seem to have an internal clock that affords them the knowledge of just how much time is left in the game. But unlike Walt Frazier, Johnny Unitas, or Steve Cauthen, most of us need an external clock. Try using a pocket watch with a large dial placed on the front table. Easy to see at a glance, such a watch allows you to check the time without constantly looking at a wristwatch, body language that says to the speaker, "Hurry up and finish, we're running out of time." If the period allotted is more than two hours, think seriously of planning a break, keeping in mind that unless planned for, a break often destroys a discussion. If you have a long period scheduled for one topic, think about a group activity as one kind of natural break.

\section{Group Work}

There is a natural hierarchy in discussion classes, from individual preparation, to small group, to class. At each stage, insights are added that were not apparent at the earlier stage. Class discussions are usually improved if preceded by leaderless small-group sessions. Scheduling those is usually a great problem, but if the subject matter or particular issue seems to lend itself to such sessions, they are often worth the trouble. If students are having trouble with the discussion format, organize smaller study group discussions before class. Small groups are a place where strong students can help weak students and shy students can more comfortably contribute, behaviors that are worth encouraging. 


\section{Ending the Class}

Discussion classes generally require that the leader formally end the class by summing up the discussion and providing it with some larger meaning in terms of theory and relationship to the rest of the course. Sometimes, however, you might want the discussion to end without any summary, to send the participants away frustrated or confused in hopes that out of that might spring some independent work to clear up the confusion. Like much of discussion pedagogy, the end of class summary has costs and benefits. You want to give some direction and control to the whole discussion, but not so much as to lose individual creativity and risk-taking. You want to convey some theory, but not so much as to suggest that every question has a right answer that can be derived from that theory. Our classes should be rich, full of excitement and intellectual value added, but in the final analysis, we want to empower our students to learn on a continuous basis - and much of that activity is self-directed.

Therefore, think carefully ahead of time whether you want to sum up and how you want to do it. If you decide on a mini-lecture, make it a good one. If you decide the topic lends itself to more reading, this is the time for suggested bibliography. In business cases, students always want to know "what happened?" Sensing long ago that they were really searching for the "right answer," I usually resist revealing it, but suggest that they go to the sources and find out, and that time would be reserved at the beginning of the next class if any wanted to report their findings. There are usually several reports. You need also to allow yourself time at the end of class to say a few things about the next discussion assignment - perhaps some added emphasis on one kind of preparation or some hints as to where to go for help in making sense out of the material. Certainly, something needs to be said about how the class just ending will relate to the next.

\section{After Class}

The after-class chaos of students looking for individual help, your rush to get to another class or meeting, and the press of students entering for the next class sometimes prevent the very important debriefing activity necessary for every discussion class. Before you get out of the room, take a good look at the board to see what the final result looks like and how it compares to what you had thought out ahead of time in your outline. Ask yourself what was covered well, what not so well, and what was missed. 
What questions worked and which ones failed? Make notes for yourself as to how you might revise the next time.

You need at this point, or some time shortly after the class ends, to go over each of the students in class and note how they did in the discussion. This review needs to be done for several reasons - to help in your judgment of them, to help get to know them better, and, most importantly, to help you think about strategies to improve individual learning.

Grading classroom participation is another of those very sticky problems for the discussion teacher. To encourage participation, you probably have to do it, but be aware of its costs. Trained as we are to grade written work, most of us have no idea how to judge verbal participation. Do you reward a student who talks a lot, but says little? Do you penalize a student for trying out new ideas that are badly off track? What about the student who just will not or just cannot seem to make any contribution? These are tough issues and go to the heart of the discussion class dilemma. I grade participation, but I can't quantify it very well. I try to reward continuous informed participation throughout the semester. I try to talk individually with those who do not seem to be participating, either to encourage some participation or to understand why there is none. Grading is a difficult task that none of us does very well. We need to share our concerns and our ideas with our colleagues.

\section{How to Start}

This article alone is not going to do much to improve your discussion teaching. Encouraging good discussions is more difficult than that. In the work I do with faculty, I stress that we all should get help from several different sources. First, watch an experienced discussion teacher teach. Sit in on several classes. Discuss the class, particularly its methodological aspects. Second, get somebody you trust to sit in on your classes and give you some honest feedback. To enrich this discussion, have the class videotaped so that you both can see what is happening while you are discussing it. Third, form a discussion group with other interested faculty to share ideas and to talk out the important teaching issues that are highlighted by the discussion method and by your thinking so deeply about the process of teaching. I have used a series of cases (included in the bibliography) about teachers in discussion classes to organize this process. Fourth, seek the feedback of your students, either in formal or informal discussion, or with some well-formulated written mechanism. Find out 
from them whether they think they are really learning more and enjoying it more. Finally, practice, practice, practice, and be your own best critic.

\section{Bibliography: Case Method and Discussion Method Teaching}

Adler, M. (1985). How to speak, how to listen. New York: Collier Books.

Andrews, J.D.W. (1980). The verbal structure of teacher questions: Its impact on class discussion. POD Quarterly, 2, 129-163.

Andrews, K.R. (Ed.). (1953). The case method of teaching human relations and administration. Cambridge: Harvard University Press.

Argyris, C. (1980). Some limitations of the case method: Experience in a management development program. Academy of Management Review, 5, 291-298.

Berger, M. (1983). In defense of the case method: A reply to Argyris. Academy of Management Review, 8, 329-333.

Brown, S., and Walter, M. (1983). The art of problem posing. Philadelphia: The Franklin Press.

Bruner, J.S. (1966). Toward a theory of instruction. Cambridge: Harvard University Press.

Christensen, C.R. (1986). Teaching and the case method. Boston: Harvard Business School Publishing Division.

Copeland, M.T. (1958). The case method of instruction. And mark an era: The story of the Harvard Business School. Boston: Little, Brown.

Elbow, P. (1986). Embracing contraries: Explorations in learning and teaching. New York: Oxford University Press.

Erskine, J.A., Leenders, M.R, and Mauffette-Leenders, L.A. (1981). Teaching with cases. London and Ontario, Canada: Research and Publications Division, School of Business Administration, The University of Western Ontario.

Fraser, C.E. (Ed.). (1931). The case method of instruction: A related series of articles. New York: McGraw-Hill.

Frederick, P. (1981). The dreaded discussion: Ten ways to start. Improving College and University Teaching 29, 109-114.

Freire, P. (1970). The pedagogy of the oppressed. New York: Herder \& Herder.

Hill, W.F. (1969). Learning through discussion. Beverly Hills, CA: Sage.

Hunt, P. (1951). The case method of instruction. Harvard Educational Review, 21, 2-19.

Hyman, R.T. (1980). Improving discussion leadership. New York: Teachers College Press, Columbia University.

Kasulis, T. (1986). Questioning. In M. M. Gilette (Ed.), The art and craft of teaching. Cambridge: Harvard University Press. 
Lang, C. (1986). Case method teaching in the community college. Newton, MA: Educational Development Center. (Comes with videotape of case teaching session. Available from Educational Development Center, 55 Chapel St., Newton, MA 02160.)

McNair, M.P., and Hersum, A.C. (1954). The case method at the Harvard Business School. New York: McGraw-Hill.

Miner, F.C. (1978). An approach for increasing participation in case discussions. Exchange: The Organizational Behavior Teaching Journal, 3, 41-42.

Reynolds, J.I. (1980). Case method in management development: Guide for effective use. Geneva, Switzerland: Management Development Series No. 17, International Labour Office.

Reynolds, J.I. (1978). There is method in cases. The Academy of Management Review, 3, 129-133.

Roethlisberger, F.J. (1977). Teaching by the case method. In G.F.F. Lombard (Ed.), The Elusive Phenomena. Boston: Division of Research, Harvard University Graduate School of Business Administration.

Rogers, C.R. (1969). Freedom to learn. New York: Chas. Merrill.

Rogers, C.R. (1965). Student-centered teaching. In C.R. Rogers (Ed.), Client-centered therapy: Its current practice, implications, and theory. Boston: Houghton Mifflin.

Sanders, N. (1966). Classroom questions: What kinds? New York: Harper \& Row.

Tedesco, P.H. (1974). Teaching with case studies. Boston: Public Information Center, Federal Reserve Bank of Boston.

Wiggins, G.P. (1988). Creating a thought-provoking curriculum. (Working Paper). Providence, RI: Coalition of Essential Schools.

The following articles are available from HBS Case Services, Harvard Business School, Boston, MA 02163:

Andrews, Kenneth. The role of the instructor in the case method.

Corey, E. Raymond. Case method teaching.

Corey, E. Raymond. The use of cases in management education.

Gragg, Charles A. Because wisdom can't be told.

Gragg, Charles A. Teachers must also learn.

Hammond, John S. Learning by the case method.

Hanson, Abby. A note to discussion teachers: Power in the classroom.

Hanson, Abby. A note to teachers on self-management.

McNair, Malcom. Tough-mindedness and the case method.

Mason, Charles. Notes to a beginning case method teacher.

Shapiro, Benson. An introduction to cases.

Shapiro, Benson. An introduction to the case method.

Shapiro, Benson. Hints for case teaching. 
The following Teaching Cases are available from HBS Case Services, Harvard Business School, Boston, MA 02163:

These cases have very complete and thoughtful teaching notes, which can be ordered as well.

\section{Assistant Professor Graham and Ms. Macomber (A, B, C)}

A shy student takes a position on a case in conflict with the other students. The professor believes her position to be correct but does not indicate so in class. As a result, the student withdraws from participation in subsequent class discussions.

\section{Bill Jones (A, B)}

Ayoung female student makes a disparaging remark about blacks during a case discussion.

\section{Bob Thompson (A, B, C)}

A young instructor is faced with the request for a grade to be raised so that a foreign student may graduate.

Case of the Dethroned Section Leader (A, B)

A young English instructor is "deposed" by members of her discussion section.

\section{Class on World Hunger (A, B)}

A disruptive incident in a case discussion class.

\section{Day the Heat Went On (A, B)}

A young female instructor hears a wolf whistle from the back of her classroom when she takes off her blazer.

Ernie Budding (A, B, C, D)

An instructor attempts to motivate his section to raise its classroom performance.

French Lesson (A, B) 
A French teacher asks a student who is not performing well in class if he has prepared for the class. The student is so upset that he leaves the room.

\section{Kurt Jacobs}

A foreign student misunderstands the nature of the class discussion and explodes in an emotional outburst against his classmates.

\section{Handicapped Heckler (A, B, C)}

A paraplegic student in a wheelchair repeatedly and belligerently interrupts a young English instructor's discussion class. Because of his condition, she hesitates to confront him.

\section{Henry Jasper (A, B)}

A new female instructor in a large university tries to help a struggling male student who reacts negatively in class to her concern.

\section{Felt as if My World Had Just Collapsed (A, B, C)}

An instructor attempts a class exercise involving black and white students. A confrontation ensues and the instructor has to deal with a difficult classroom situation.

\section{Night School Episode (A, B)}

A female instructor is challenged by an older conservative student about her use of sexually explicit words in her classrocm.

\section{One Teacher's Nightmare (A, B)}

A young history teacher in a large southern university is pressured to raise the grade of a member of the football team.

\section{Section Just Took Over}

A section of MBA's discussing a functional business problem becomes interested in a related question of social responsibility and proceeds to run its own discussion, ignoring the instructor's attempts to get the class back on track. 


\section{Suzie Simons (A, B)}

A female student admits to her instructor that her previous work had been prepared by her boyfriend.

\section{The Offended Colonel (A, B)}

A student is offended by the use of profanity in a case discussion.

\section{Trevor Jones}

A role-playing exercise turns into a real-life drama as a student takes his role too personally.

\section{We're Just Wasting Our Time}

An instructor is having a particularly difficult time getting his class to engage in productive case discussion.

The following paper is available from Center for Applied Research, Lubin Schools of Business, Pace University, New York, NY 10038:

Silverman, R., and Welty, W.M. (1988). Mainstreaming exceptional students: A series of cases.

A collection of cases set in elementary and secondary schools posing teaching problems revolving around mainstreaming issues. These cases are designed to be used in undergraduate education classes. Teaching notes to accompany the collection are available on request. 